\title{
A FETUS WITH PARTIAL TRISOMY 3 (p21-pter) DETECTED BY PRENATAL DIAGNOSIS
}

\author{
Kaoru Suzumori, Takiko KoIshi, Minoru ManzaI, \\ and Yoshiaki YAGAMI \\ Department of Obstetrics and Gynecology, Nagoya City University, \\ Medical School, Mizuho-ku, Nagoya, Aichi 467, Japan
}

\begin{abstract}
Summary A fetus with trisomy 3 (p21-pter) was detected prenatally in the pregnancy of a mother with $t(3 ; 11)(\mathrm{p} 21 ; \mathrm{q} 25)$. The aborted fetus had various kinds of congenital anomalies compatible with partial trisomy 3 .
\end{abstract}

\section{INTRODUCTION}

The improvement in antenatal diagnosis over the past decade has been amply documented. Prenatal amniocentesis is a widely accepted procedure for the detection of various kinds of genetic disorders. It is particularly well established in the field of chromosomal diorders.

Meanwhile, the technical improvements in human cytogenetics have made the identification of each human chromosome possible. Numerous banding techniques have provided a variety of new and exciting informations.

In order to provide prenatal diagnosis in several conditions that are associated with reciprocal translocations and in which chromosomal abnormality has never been recognized by a non-banded technique, the banding identification technique should be utilized.

This article reports a fetus with trisomy 3 (p21-pter) due to an adjacent-1 segregation of a maternal reciprocal translocation $\mathrm{t}(3 ; 11)(\mathrm{p} 21 ; \mathrm{q} 25)$.

\section{CASE REPORT}

A pregnant, 27-year-old, phenotypically normal woman was referred to our hospital for genetic counseling. Her husband was 30 years old who was in good health. There was no apparent consanguinity. This woman was first seen in the 17 th week of gestation.

At the age of 20 , she had a first-trimester induced abortion for economic reasons. Her second pregnancy, one year previously, resulted in a term male infant weighing $4,230 \mathrm{~g}$, who died four months after birth from congenital heart disease.

Received June 21, 1982 
The infant had physical anomalies consisting of harelip, cleft palate and distinct heart murmur.

Cytogenetic studies revealed 46,XY,Cp + karyotype from cultured leucocytes, but further confirmation of this abnormal long $\mathrm{C}$ chromosome was not carried out, because the analysis by band staining was not practicable at the hospital where this baby was born.

Immediately after her visit, chromosomal analyses of available family members were initiated by the banding technique. The husband had a normal chromosome constitution, but preparations from the wife, her mother and her sister revealed to be balanced translocation carriers. Their karyotypes were interpreted as a reciprocal translocation between the short arm of chromosome No. 3 and the long arm of No. 11. The breakpoints occurred at bands $3 \mathrm{p} 21$ and $11 \mathrm{q} 25$ forming the reciprocal translocation $\mathrm{t}(3 ; 11)$ (p21; $\mathrm{q} 25)$ (Fig. 1).

Through these findings and an explanation on the consequences of gametogenesis in an individual carrying a reciprocal translocation, it was concluded that the risk of bearing an affected fetus in the current pregnancy would be very high.

33 der

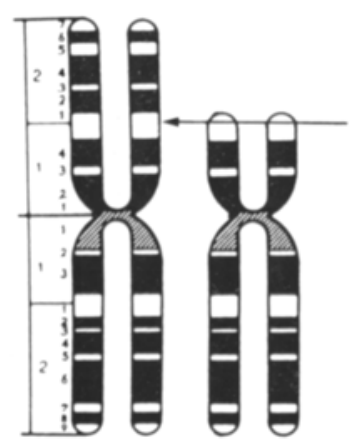

11 11der

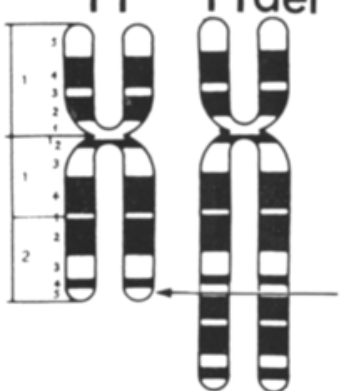

A
3 3der
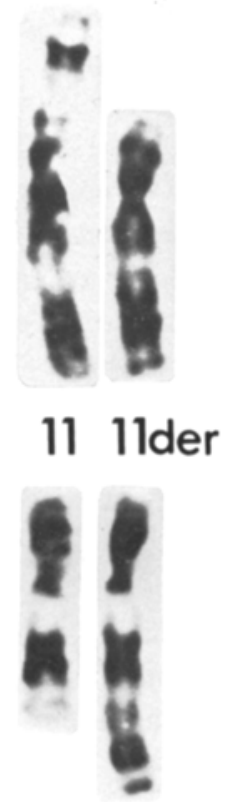

B

Fig. 1. A: Schematic illustrations of normal and derivative chromosomes 3 and 11 . Arrows indicate breakpoints. B: G-banded chromosomes 3 and 11 from the mother; $t(3 ; 11)(\mathrm{p} 21 ; \mathrm{q} 25)$. 


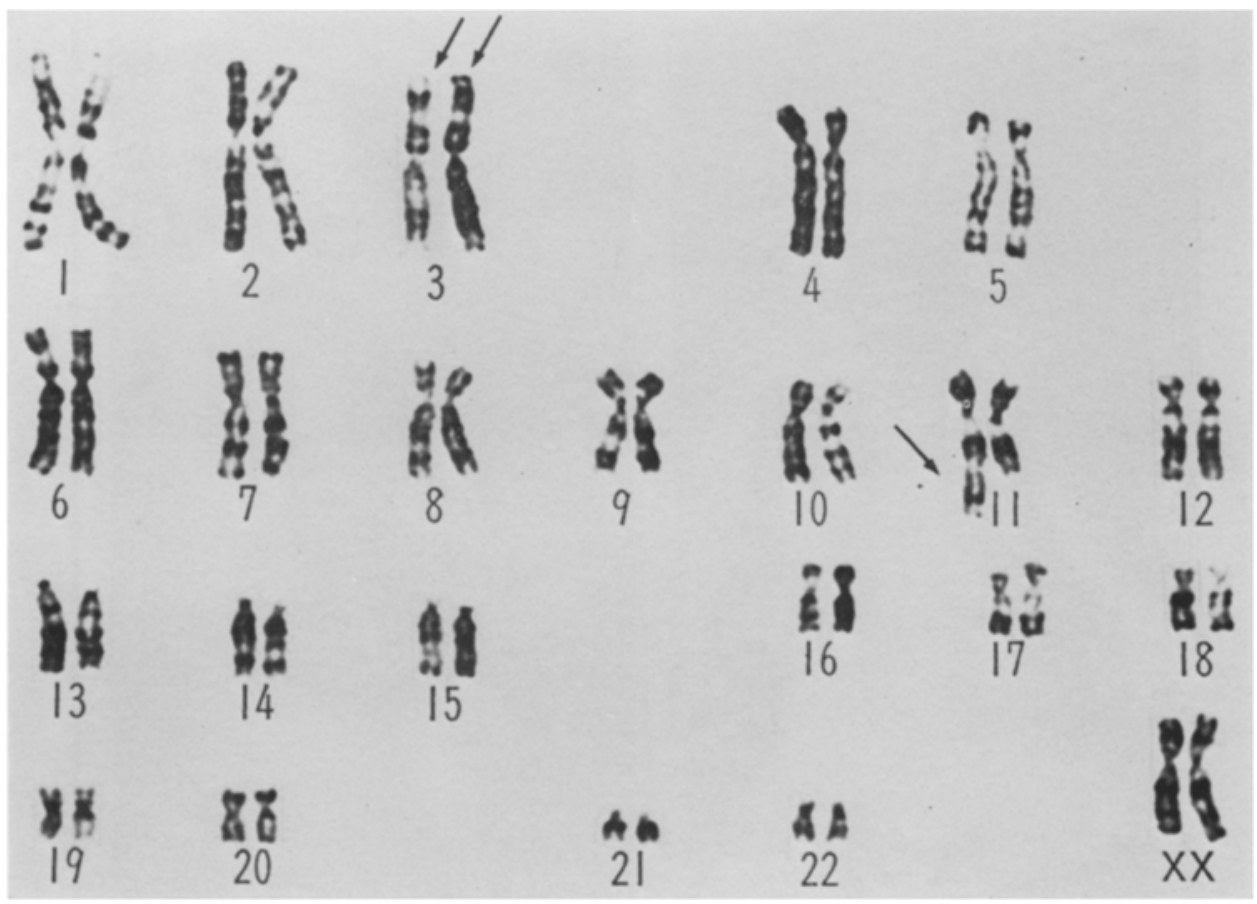

Fig. 2. Karyogram of the amniotic fluid cell.

The parents decided to undergo the prenatal diagnosis. Amniocentesis was performed at 19 weeks of gestation. After 10 days cultivation, amniotic fluid cells showed a normal modal number of 46 chromosomes and both No. 3 chromosomes were normal. The long arm of No. 11 was markedly elongated in all of the cells analyzed. This indicated the presence of a trisomy for segment $3 \mathrm{p} 21-3 \mathrm{pter}$ as a result of adjacent-1 segregation in the maternal gamete. The karyotype, therefore, was $46, X X$, der(11),t( $3 ; 11)$ (p21;q25)mat (Fig. 2).

Chromosomal findings strongly suggested a fetal abnormality. After discussion with the parents, therapeutic abortion was advised. The pregnancy was terminated at 22 weeks of gestation by vaginal suppositories of Prostaglandin $E_{1}$ [16,16-dimethyltrans- $A^{2}-\mathrm{PGE}_{1}$ methyl ester (ONO-802), Ono Pharm. Comp., Ltd., Japan].

\section{PATHOLOGIC EVALUATION}

Examination of the abortus revealed a female fetus weighing $480 \mathrm{~g}$ and measuring $25 \mathrm{~cm}$ in crown-rump length. Multiple congenital anomalies were evaluated (Fig. 3). Congenital anomalies included a round-shaped face with distinct ocular hypertelorism, tightly closed and narrow palpebral fissures, complete bilateral harelip and cleft palate, and a small and receding chin. The ears were normally set, 


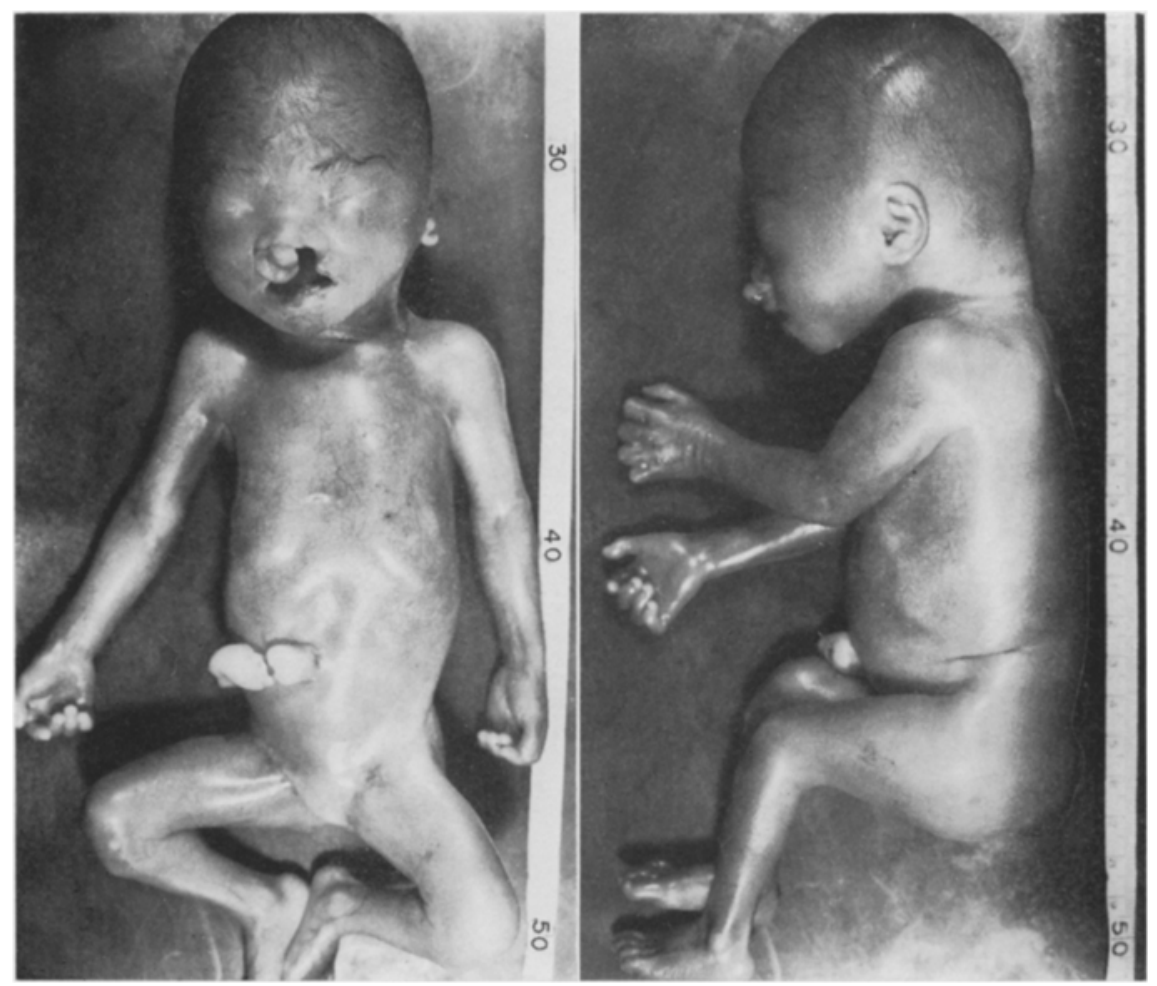

Fig. 3. The abortus. Frontal and lateral views.

but exhibited a poor molding of the helix and antehelix. The neck was short and the skin at the back of the neck was protuberant. The chest was narrow and the poorly developed nipples were widely spaced. The umbilicus contained three vessels. Narrowness of the pelvis was present. The external genitalia were specific, and the vulvar structures, including the urethral opening were completely absent. Absence of the genitalia resulted in a smooth unblemished perineum. But the anus was perforated in the normal position. The limbs were short in relation to the trunk. On the lumbosacral midline, a $2.0 \times 2.0 \mathrm{~cm}$ soft protrusion covered by normal skin was found. The sac showed fluctuation on palpation. A narrow osseous defect connecting the intraspinal space with the sac was confirmed by opening the sac (Fig. 4).

X-ray examination revealed that the skeletal system was normal.

Autopsy disclosed a ventricular septal defect. No aberrations were detected in the lungs, trachea, esophagus, stomach, duodenum, colon or muscular system. However, the lack of urinary drainage had resulted in hydronephrosis, hydroureter, and bladder distension. The internal genital organs were found on the back of the distented bladder. The gonads and the fallopian tubes were normal, but the lower end of the reproductive tract disappeared in the depths of the pelvic wall. 

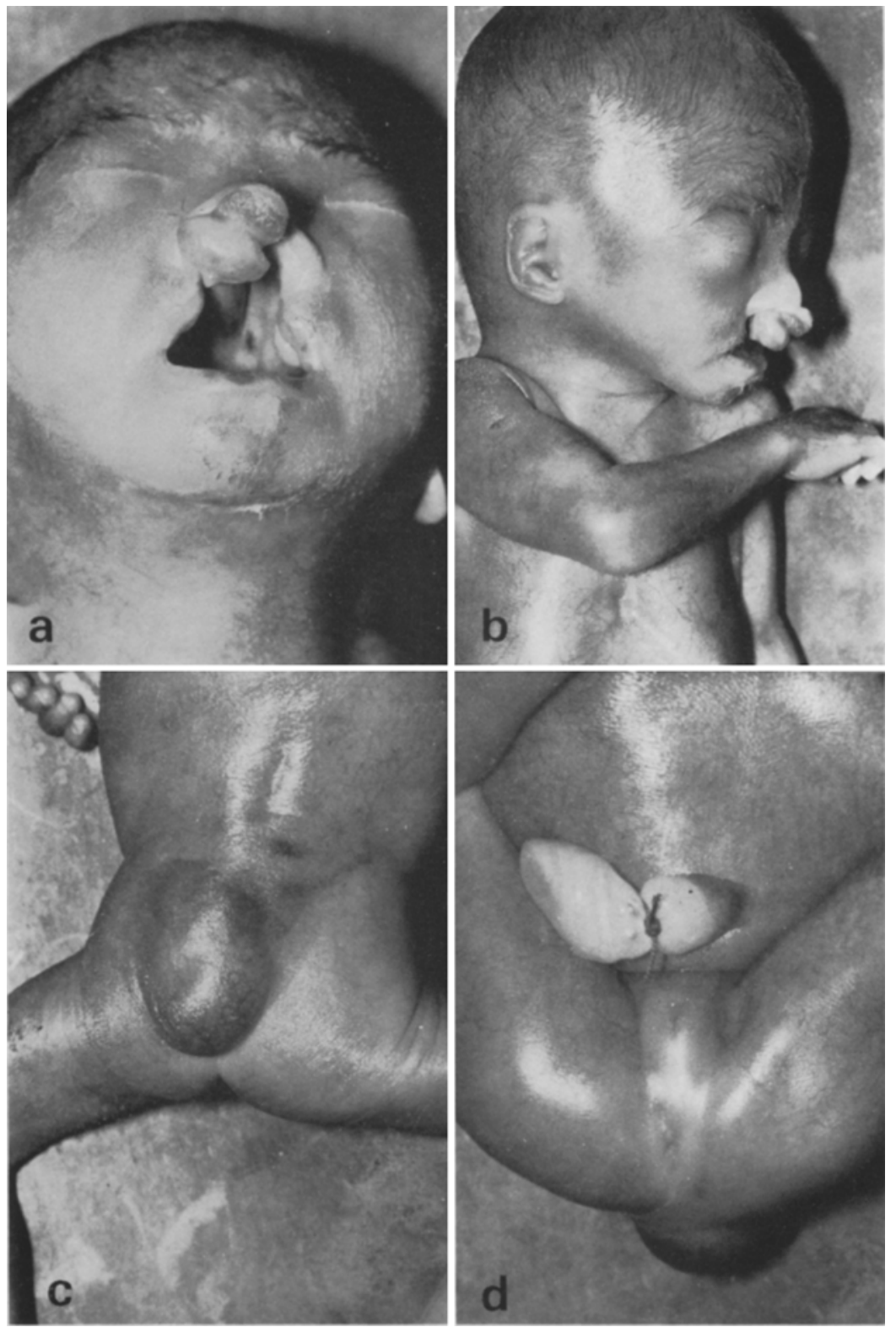

Fig. 4. a: Small mouth, cleft lip and palate. b: Poor molding of the external ear, receding and small chin. c: Spina bifida. d: The external genitalia without vulvar structure.

Okajima's method was used for the dermatoglyphic analysis (Okajima, 1975). The dermal patterns of the fetus were as follows: Right hand: Palmar formula, 11.11.9.5' $-\mathrm{t}-\mathrm{A}^{\mathrm{u}} . \mathrm{O} /$ V.O.L.O; atd angle $=49^{\circ}$; digits $=\mathrm{W}, \mathrm{U}, \mathrm{W}, \mathrm{W}, \mathrm{U}$. Left hand: 

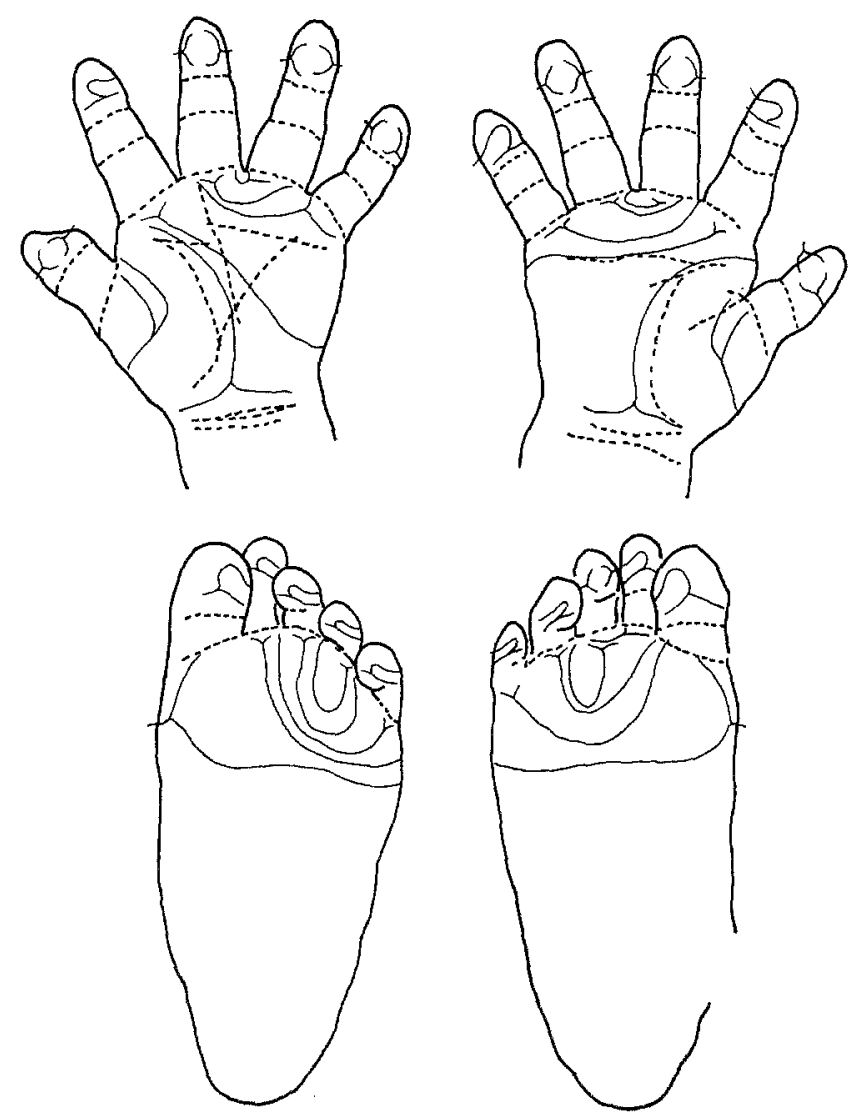

Fig. 5. Dermatographic patterns of the hands and feet.

Palmar formula, 11.9.7.3-t-A u.O/V.O.L.O; atd angle $=47^{\circ}$; digits $=$ W.U.W.W.W. Right sole: Plantar formula, 13.13.9.9-Lf O.Ld $. O . O . O . V$; toes $=L^{f}, L^{f}, W, L^{f}, L^{f} . \quad$ Left sole: Plantar formula, 11.9.7.5-Lf.O.Ld O.O.O.V; toes $=L^{f} . L^{f} \cdot L^{f} \cdot L^{f} \cdot L^{f}$ (Fig. 5).

\section{DISCUSSION}

To our knowledge, distinct partial trisomy for the distal short arm of chromosome 3 was first reported by Rethoré et al. (1972).

Since then, there have been reported of eight additional cases with this condition, almost all having a parent with a balanced translocation involving 3p (Sachdeva et al., 1974; Ballesta and Vehi, 1974; Say et al., 1976; Yunis, 1978; Surana et al., 1977; Parloir et al., 1979; Francke, 1978; Tsukino et al., 1981). The extent of the duplicated segment varied in each case. In addition, the $3 p$ duplication was associated with a terminal deletion of the recipient chromosome involving eight different chromosome regions $(4 q, 7 p, 7 q, 10 q, 12 q, 15 p, 18 q$ and $22 q)$. The 
differences in the duplicated segment and the loss of genetic material in the telomeric region of the recipient chromosome appear to be attributable to clinical variation in some cases. However, partial trisomy $3 p$ is connected with a certain constellation of congenital anomalies sufficiently characteristic to allow the delination of a new syndrome (Grouchy and Turleau, 1977).

The most consistent clinical manifestation and growth data in the reported patients with chromosomally proven $3 p$ trisomy syndrome are listed in Table 1.

Duplication/deficiency of autosomal material creates a genetic imbalance that adversely influences fetal development. Thus, growth deficiency of prenatal onset is a consistent manifestation in neonates with autosomal abnormalities. As listed in Table 1, however, the growth data are not different from those found in the general population. As for our case, body weight was $480 \mathrm{~g}$ and the crown-rump length was $20 \mathrm{~cm}$ (mean, $442.2 \mathrm{~g}$ and $16.9 \mathrm{~cm}$ for this gestational age, respectively). This indicates that growth deficiency of prenatal onset is not a consistent manifestation of this syndrome.

Table 1. Clinical findings in patients with partial $3 p$ trisomy (13 cases).

\begin{tabular}{|c|c|c|}
\hline & & Our case \\
\hline Sex & $110^{7}$ and 2 早 & 우 \\
\hline Mean birth weight at term & $3,464 \mathrm{~g}$ & $480 \mathrm{~g}(22 \mathrm{w}$. Gest.) \\
\hline Mean length at birth & $49.1 \mathrm{~cm}$ & $20 \mathrm{~cm}$ \\
\hline \multicolumn{3}{|l|}{ Phenotype } \\
\hline \multicolumn{3}{|l|}{ Craniofacial } \\
\hline Microcephaly & $5 / 13$ & - \\
\hline Square-shaped face & $8 / 11$ & $?$ \\
\hline Frontal boss & $11 / 11$ & - \\
\hline Temporal depression & $6 / 9$ & - \\
\hline Prominent cheek & $9 / 9$ & $?$ \\
\hline Hypertelorism, broad nasal bridge & $9 / 11$ & + \\
\hline Epicanthus & $8 / 11$ & $?$ \\
\hline Cleft lip/palate & $3 / 10$ & + \\
\hline Micrognathia and/or retrognathia & $8 / 11$ & + \\
\hline Short neck & $8 / 10$ & + \\
\hline Congenital heart defect & $11 / 13$ & + \\
\hline Intestinal stenosis or atresia & $5 / 7$ & - \\
\hline Renal abnormalities & $2 / 8$ & + (hydronephrosis) \\
\hline Hypoplastic genitalia & $8 / 10$ (male) & + (vulvar agenesis) \\
\hline Predominance of whorl on digits & $6 / 7$ & + \\
\hline Deep crease on soles & $3 / 5$ & - \\
\hline
\end{tabular}


The craniofacial manifestation is of much interest because the incidence of abnormalities in this region is high in neonates with $3 p$ trisomy. Microcephaly with brachycephaly is commonly present, and the face is characterized by a square shape, high and prominent forehead, temporal depression, long philtrum and short nose. Distinct hyperterolism and epicanthus are usual. Macrostomia with falling corners of the lip is common and micrognathia and retrognathia are also seen. Several patients have presented a complete harelip and cleft palate. In the present case, we did not find all of these abnormalities in the craniofacial region. Our observation suggests that craniofacial features are not distinct in fetuses aborted in the second trimester because late intrauterine fetal or postnatal life may have an effect on the overall development of the facial appearance.

Congenital heart defects, mostly often a ventricular septal defect or an atrial septal defect, are found in the majority of cases. Our case showed ventricular septal defect on postmortem examination.

Of the 13 cases reported in the literature, there were only two female patients at birth. The genitalia are a characteristic phenotype manifestation of this syndrome. Micropenis and/or undescended testes were present in nine of the 11 males, but there have not been precise descriptions of the genital organs of the two females. In our female case, the most distinctive abnormality not reported previously is agenesis of the external genitalia, including the external urinary orifice. The duration of fetal life may vary inversely with renal function. The anuric infant may reach full term, but the fetus with kidneys which produce urine and without allowance for urine flow may aquire a bladder so distended that it literally fills the abdomen and interferes with the development of the other organs. This circumstance conceivably can not maintain fetal life until full term. Therefore, such a fetus would probably result in intrauterine death. Our female case with severe deformity supports Yunis's idea suggesting that trisomy for the distal end of the short arm of chromosome 3 may be more lethal for female subjects.

During subsequent pregnancy, prenatal cytogenetic study was performed again. A normal male karyotype was found and a normal boy was born at 40 week's gestation, birth weight $3,300 \mathrm{~g}$.

Acknowledgment This study was supported in part by the grants from the Ministry of Health and Welfare of Japan and the Japan Association for Maternal Welfare of the Research of Handicapped Children.

\section{REFERENCES}

Ballesta, F. and Vehi, L. 1974. Trisomie partielle pour la partie distale bras du chromosome 3. Ann. Génét. (Paris) 17: 287-290

Franke, U. 1978. Clinical syndromes associated with partial duplications of chromosome 2 and 3: $\operatorname{dup}(2 \mathrm{p}), \operatorname{dup}(2 \mathrm{q}), \operatorname{dup}(3 \mathrm{p}), \operatorname{dup}(3 \mathrm{q})$. Sex Differentiation and Chromosomal Abnormalities, (eds.) Summitt, R.L. and Bergsma, D. The National Foundation-March of Dimes Birth Defect: Original Article Series, 14-6C, pp. 191-217, Alan R. Liss, Inc., New York.

Jpn. J. Human Genet. 
Grouchy, J. de. and Turleau, C. (ed.) 1977. Partial 3p Trisomy in Clinical Atlas of Human Chromosomes, John Wiley, New York, pp. 10-12

Okajima, M. 1975. Development of dermal ridges in the fetus. J. Med. Genet. 12: 243-250

Parloir, C., Fryns, J.P., and Bergh, H.V. 1979. Partial trisomy of the short arm of chromosome 3 (3p25-3pter). A distinct clinical entity. Hum. Genet. 47: 239-244

Rethoré, M.O., Leheune, J., Carpentier, S., Prieur, M., Dutrillaux, B., Seringe, P., Possier, A., and Job., J.C. 1972. Trisomie pour la patie distale du bras court du chromosome 3 chez trois germains. Premier exemple d'insertion chromosomique ins $(7 ; 3)(\mathrm{q} 31 ; \mathrm{p} 21 ; \mathrm{p} 26)$. Ann. Génét. (Paris) 15: 159-165

Sachdeva, D., Smith, G.F., and Justice, P.C. 1974. An unusual chromosomal segregation in a family with a translocation between 3 and 12. J. Med. Genet. 11: 303-305

Say, B., Barber, N., Bobrow, M., Jones, K., and Coldwell, J.G. 1976. Familial translocation (3p15) with partial trisomy for the upper arm of chromosome 3 in two sibs. J. Pediatr. 88: $447-450$

Surana, R.B., Braudo, M.E., Conen, P.E., and Slade, R.H. 1977. 46,XY,t(3;22) (p2;q13) resulting in partial trisomy for the short arm of chromosome 3. Clin. Genet. 11: 201-206

Tsukino, R., Omori, H., Uemura, S., Kodama, A., and Koike, M. 1981. A case of partial 3p trisomy $[46, \mathrm{XY},-18,+\operatorname{der}(18), \mathrm{t}(3 ; 18)(\mathrm{p} 24 ; \mathrm{q} 22)]$. Proc. Jpn. Acad. 57: 89-94

Yunis, J.J. 1978. Trisomy for the distal end of the short arm of chromosome 3. Am. J. Dis. Child. 132: $30-33$ 